\title{
Bilateral Pneumothorax
}

and Subcutaneous

Emphysema following

Endoscopic Retrograde

Cholangiopancreatography

with Sphincterectomy

BY TAJDA KEBER, KLEMEN MOJŠKERC, JANA MAKUC

\section{Abstract}

Endoscopic retrograde cholangiopancreatography (ERCP) is a valuable diagnostic and therapeutic procedure in the management of pancreatic and extrahepatic biliary tract diseases. Although rare, it is related to several complications including retroperitoneal duodenal perforation. The perforation results in air accumulation in the retroperitoneal, pleural or subcutaneous space. We present a case of 63-year-old female with massive bilateral pneumothorax and subcutaneous emphysema following therapeutic ERCP.

Key words: endoscopic retrograde cholangiopancreatography, pneumothorax, subcutaneous emphysema, complications of endoscopic retrograde cholangiopancreatography

\section{Introduction}


Endoscopic retrograde cholangiopancreatography (ERCP) has become mainly a therapeutic procedure in the light of the fast development of imaging techniques in the last decade. The main risk factors for complications during the procedure are difficult bile duct cannulation, continuous air insufflation, repeated attempts to cannulate the papilla, duration of the procedure, anatomical abnormalities, diverticula in the periampular area, cirrhosis, sphincter of Oddi dysfunction and previous gastrointestinal surgery. The most common complications are pancreatitis (1.8\%) and haemorrhage (1.13\%). (1) An uncommon complication (0.57\%), but one of the most feared, with a high mortality rate, is air leakage. It originates either from injury of the duodenum and small bowel or extrahepatic bile duct system as a direct consequence of hollow organ wall perforation or ruptured alveoli. Pneumothorax is an extremely rare but possibly fatal complication if not diagnosed properly. Only sporadic cases are described. (1-3) Here we present a patient with multiple risk factors, including repeated attempts and difficulties of cannulation due to anatomical abnormalities, continuous air insufflation and history of gastrointestinal surgery.

\section{Case report}

A 63-year-old female with a history of previous ERCP due to cholelithiasis presented with repetitive symptomatic cholelithiasis seven years after cholecystectomy. She underwent abdominal ultrasound imaging which showed enlarged intra- and extrahepatic biliary ducts and ductus choledochus. During an elective ERCP, which lasted 54 minutes, there were problems locating and opening the papilla that was already iatrogenically modified due to previous endoscopic sphincterotomy (EPT). There was small active bleeding at the site of papillotomy after additional EPT. The haemorrhage ceased spontaneously; haemostasis was supported with an adrenalin injection. There were problems with balloon catheter insertion accompanied by several balloon jams during the procedure. Several concrements were extracted. During the removal of the duodenoscope, the patient became hypoxaemic and complained of moderate abdominal pain. An immediate abdominal radiograph showed free abdominal air. The patient was transferred to the surgical intensive 
care unit after immediate consultation with the attending abdominal surgeon. Respiratory insufficiency persisted for the next hour. It was accompanied by the development of progressive subcutaneous emphysema over the chest and neck region. Abdominal and chest imaging showed retroperitoneal air, an extensive right-sided pneumothorax, with complete right pulmonary lobe collapse, and a less prominent left-sided pneumothorax (figure 1). Immediate right-sided thoracic drainage resulted in rapid clinical improvement of the patient's condition. The residual left-sided pneumothorax was resolved by additional left-sided drainage. Slight bleeding was noticed in the nasogastric drainage applied afterwards. Leucocytosis was the only abnormality present in laboratory findings. The patient was transferred to the tertiary surgical department for surgical treatment of a small retroperitoneal duodenal perforation in the ampullary region which was found and successfully closed during surgery. The patient's further clinical course was uncomplicated and she made a full recovery.

\section{Discussion}

Perforation after ERCP usually occurs in the retroperitoneal portion of the duodenum and results in retroperitoneal collection of free air. (4) Retroperitoneal perforation is usually related to extensive sphincterectomy beyond the intramural portion of the bile and pancreatic ducts and is classically manifested by abdominal pain, fever and leucocytosis. (3) There can be symptoms such as unrest, tachycardia, hypoxemia or subcutaneous emphysema. (5) Free air is not an uncommon finding on computed tomography (CT) scans after ERCP, even in the absence of obvious perforation. It can be found in up to $29 \%$ of cases after sphincterectomy, suggesting that in the majority of cases this is a subclinical problem not requiring specific therapy. $(2,5)$

There is continuity along the neck, thorax and abdomen. Air rising in one of these regions could reach another area by travelling along the fascial planes. (6) After a retroperitoneal perforation, free air escapes from the duodenum to the right anterior pararenal space. The air flows to the posterior pararenal compartment from where it can easily reach the diaphragmatic oesophageal hiatus and the foramen of Morgagni. It 
spreads along the fascial planes to subcutaneous tissue, leading to subcutaneous emphysema, or diffuses to the mediastinum, causing pneumomediastinum. Finally, mediastinal air can gain access to the pleural cavity due to rupture of the parietal pleura. $(2,3,5,6)$ Pneumothorax is usually right- sided or bilateral and accompanied by pneumomediastinum, pneumoretroperitoneum and subcutaneous emphysema. (5)

Retroperitoneal air can be found following insufflation of pressurized air in order to maintain the patency of the gastrointestinal or biliary lumen during ERCP in combination with co-existing mucosal disruption or a small iatrogenic perforation. (2) Air diffuses through the perineural and perivascular sheets which are damaged by the pressure that the endoscope exerts on the wall of the duodenum. (4)

Our patient presented with abdominal pain, hypoxemia and subcutaneous emphysema followed by leucocytosis. A small retroperitoneal perforation in the ampullary region, discovered during surgery, was probably caused by one of the balloon-stone jams. Indices of free peritoneal air first appeared in the middle of the procedure (figure 2). This finding is a result of subsequent abdominal radiographs, indicating that the perforation took place before anything unusual was noticed. Consequently, with large amounts of air insufflated during the multiple stone extractions, the free abdominal air pressure rose high enough to disrupt the natural borders, and rushed along the low resistance fascial planes. That caused bilateral pneumothorax, pneumomediastinum and subcutaneous emphysema.

An alternative pathway of pneumothorax formation is through pores in the diaphragm formed either congenitally or acquired (porous diaphragm syndrome). These may allow air to move between the abdominal and thoracic cavity. (5)

Another possibility in creating pulmonary interstitial emphysema is alveolar rupture due to increased intrathoracic pressure secondary to inflated air or vomiting following ERCP. $(2,5)$ There may be no abdominal symptoms and no intraperitoneal free air. (7) 
The majority of patients with retroperitoneal air and consequential pneumothorax can be managed conservatively, with administration of intravenous antibiotics, fasting and pleural drainage. When initial conservative treatment fails, surgical closure of the leak is the treatment of choice. (7) According to local policy, early and successful surgical intervention was indicated in our case. The best therapeutic approach it is yet to be discovered.

In conclusion, smaller volumes of insufflated air can help prevent complications. Continuous abdominal radiographic evaluation can be helpful in the detection of free abdominal air even, in the absence of any clinical indices. 


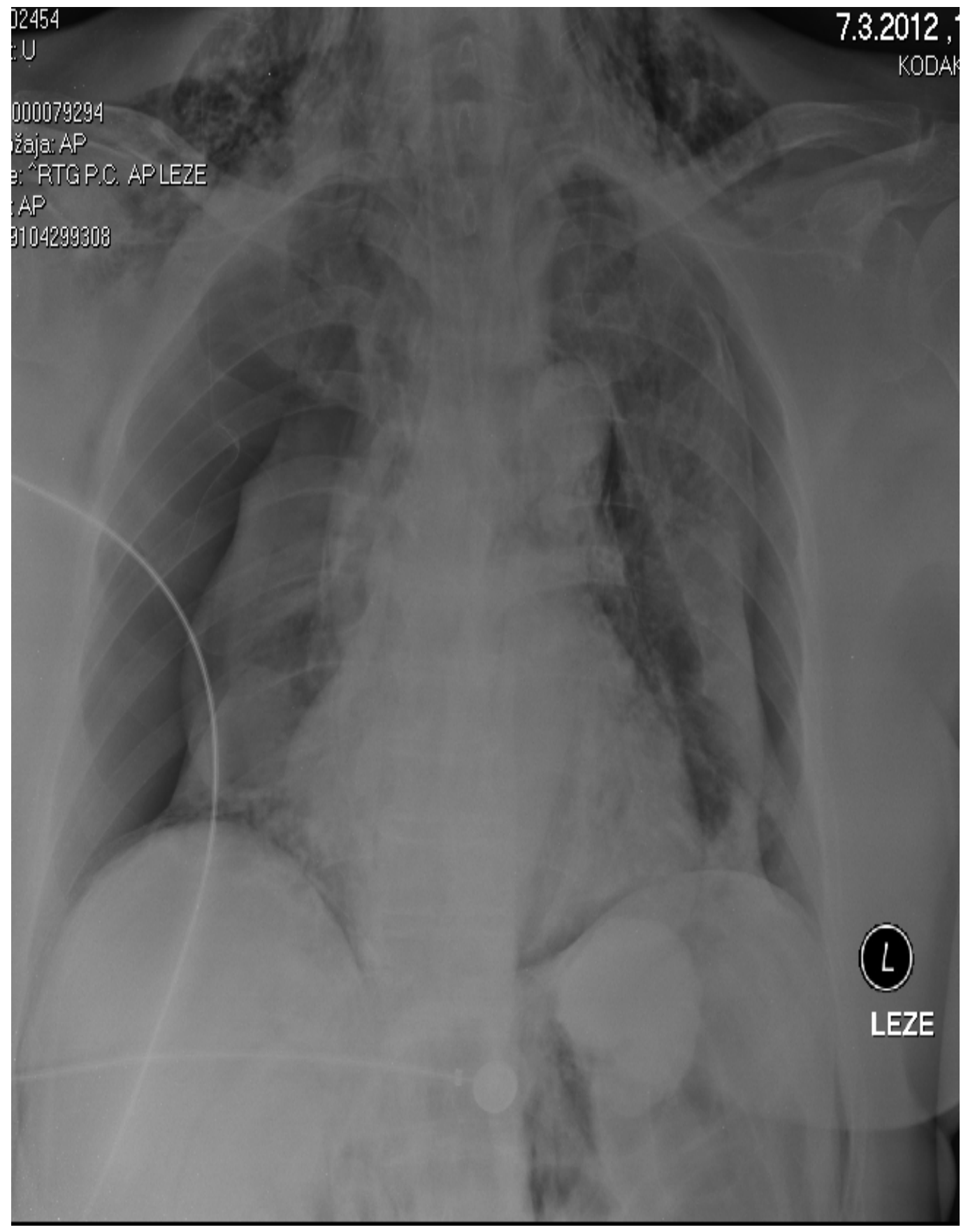

Figure 1. Chest radiograph revealing the presence of bilateral pneumothorax and subcutaneous emphysema 


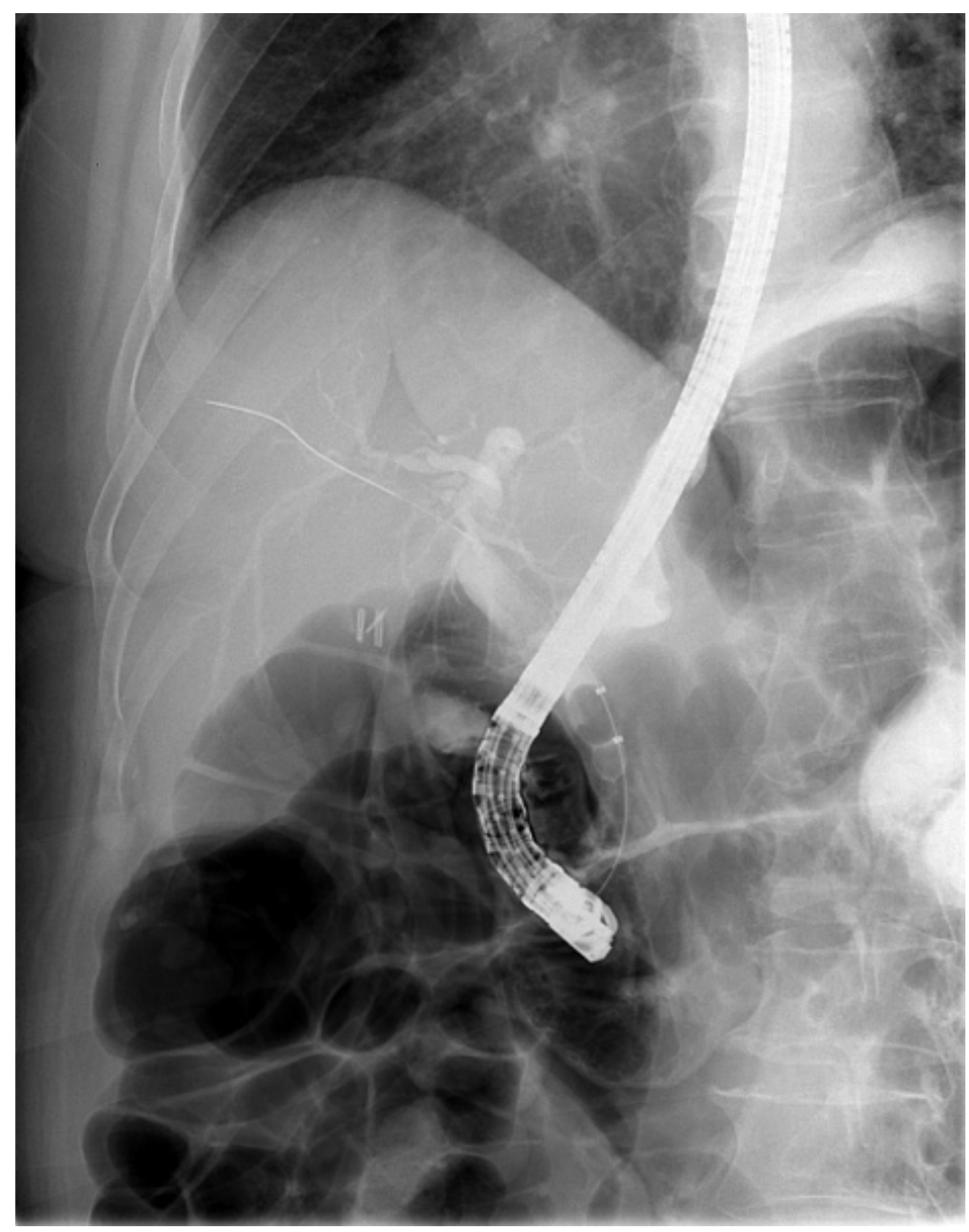




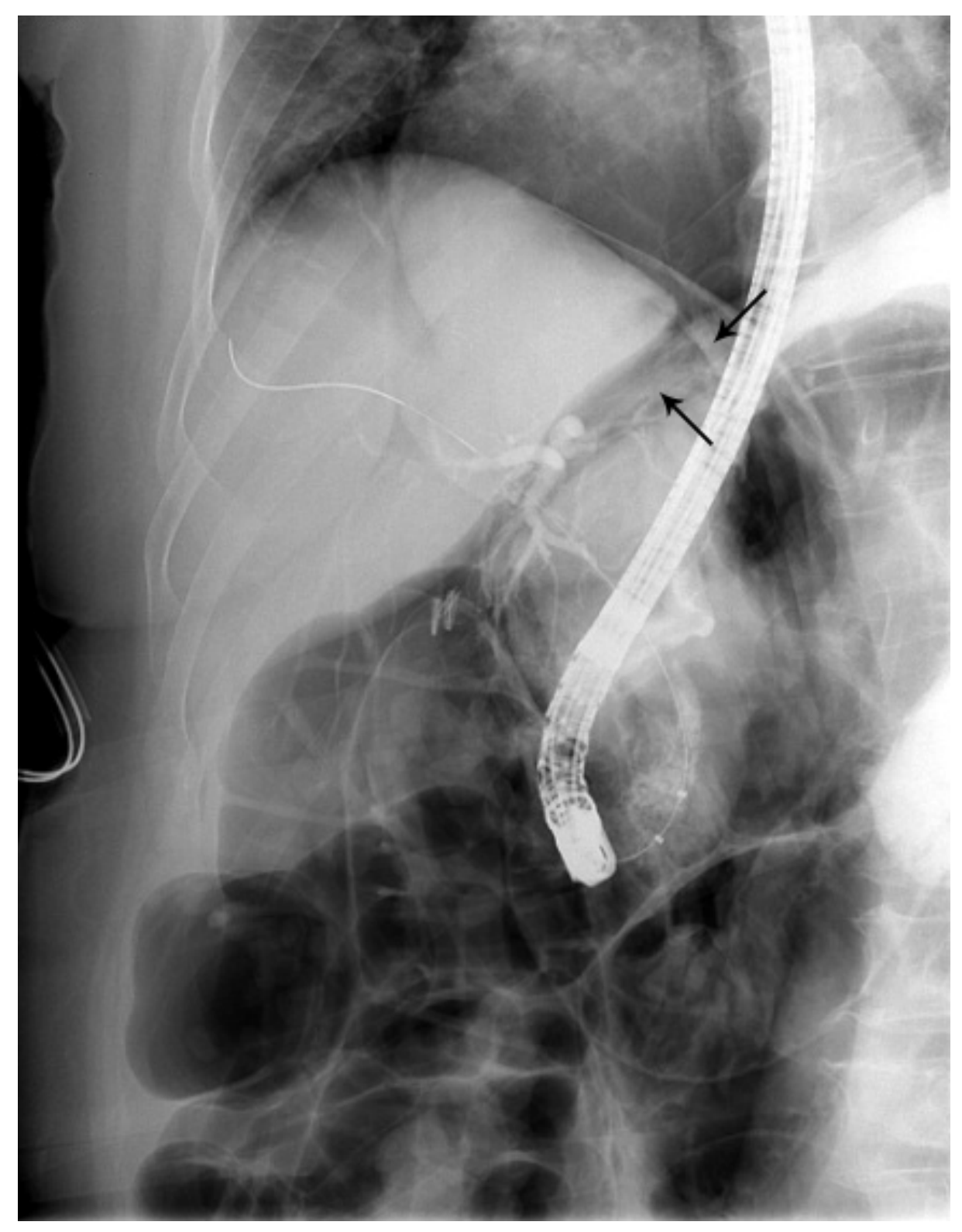

Figure 2. Radiographs taken in the middle of the procedure showing: A no free air visible, B free air in the abdominal cavity (the edge of the liver is clearly seen) - arrows.

\section{References}

1. Masci E, Toti G, Mariani A, Curioni S, Lomazzi A, Dinelli M, et al. Complications of Diagnostic and Therapeutic ERCP: A Prospective Multicenter Study. AJG 2001;96(2):417-23.

2. Papamichail M, Nikolaidis N, Anastasiou E, Sidirokastritis G, Prigouris P. Massive Subcutaneous Emphysema following Endoscopic Retrograde Cholangiopancreatography with Sphincterectomy. Case Rep

Gastroenterol 2010;4:399-403. 
3. Schiavon LL, Rodrigues RA, Nakao FS, DiSena VO, Ferrari AP, Libera ED Jr. Subcutaneous Emphysema, Pneumothorax and Pneumomediastinum Following Endoscopic Sphincterotomy. Gastroenterology Research 2010;3(5):216-8.

4. Maturana Ibáñez V, Ferrer Márquez M, Moreno Serrano A, Rodríguez Morillas D, Belda Lozano R. Management of Retreopneumoperitoneum After ERCP. Cir Esp 2013;91:608-9.

5. Schepers NJ, van Buuren HR. Pneumothorax Following ERCP: Report of Four Cases and Review of Literature. Dig Dis Sci 2012;57:1990-5.

6. Alexiou K, Sakellaridis T, Sikalias N, Karanikas I, Economou N, Antsaklis G. Subcutaneous emphysema, pneumomediastinum and pneumoperitoneum after unsuccessful ERCP: a case report. Cases Journal 2009;2:120.

7. Neofytou K, Petrou A, Savva C, Petrides C, Andreou C, Felekouras E, et al. Pneumothorax Following ERCP: Report of Two Cases with Different Patophysiology. Case Reports in Medicine vol. 2013, Article ID 206564, 4 pages, 2013. doi:10.1155/2013/206564

CORRESPONDENCE TO:

Tajda Keber

Department of Internal Medicine

General Hospital Slovenj Gradec

Gosposvetska 1, SI-2380 Slovenj Gradec, Slovenia

Phone: +38628823400

Fax: +38628823505

E-mail: tajda.keber@sb-sg.si

Article printed from Signa Vitae: http://www.signavitae.com

URL to article: http://www.signavitae.com/2015/12/bilateralpneumothorax-and-subcutaneous-emphysema-followingendoscopic-retrograde-cholangiopancreatography-withsphincterectomy/

Copyright (C) 2015 Signa Vitae. All rights reserved. 